\title{
Latinx Communities and Academic Trajectories
}

\author{
Lisceth Brazil-Cruz, Laura Grindstaff, and Yvette G. Flores
}

\begin{abstract}
This chapter will focus on why the Latina experience is critical to understanding current efforts to diversify the academy in the United States. We discuss the demographic realities of Latinx representation in higher education, the various ways in which Latinx scholars are marginalized, and what's currently known about "best practices" when seeking excellence and inclusion through institutional diversity. We stress the importance of intersectionality in understanding and addressing the underrepresentation of Latina scholars in STEM.
\end{abstract}

Keywords Latinx $\cdot$ Diversity $\cdot$ Intersectionality $\cdot$ Academia $\cdot$ Discrimination Marginalization

\section{Latinas in STEM}

According to U.S. Census projections, the Hispanic/Latinx population in the United States will increase from 58 million in 2016 to 119 million in 2060 (Flores, 2017; Krogstad, 2014). Despite this dramatic change, the numbers pursuing degrees in STEM fields is not growing at the same pace (Hess et al., 2013; Sonnert et al., 2007). As we'll explain in more detail later in this chapter, the Census uses the term Hispanic to refer to people presently in the United States from Spanish-speaking countries. Latino/a is sometimes preferred, particularly in California, because it more

\author{
L. Brazil-Cruz ( $\square)$ \\ UC Davis ADVANCE Program, University of California, Davis, Davis, CA 95616, USA \\ e-mail: lizcruz@ucdavis.edu; lbrazil@yccd.edu \\ Institutional Effectiveness, Woodland Community College, 2300 E. Gibson Road, Woodland, CA \\ 95776, USA \\ L. Grindstaff \\ Department of Sociology, University of California, Davis, Davis, CA 95616, USA \\ e-mail: lagrindstaff@ucdavis.edu

\section{Y. G. Flores} \\ Department of Chicana/o Studies, University of California, Davis, Davis, CA 95616, USA \\ e-mail: ygfloresortiz@ucdavis.edu
}


broadly refers to people of Latin American ancestry, including Brazil. In recent years, the term Latinx has emerged as a more inclusive alternative because it specifically encompasses those who are nonbinary, genderqueer or genderfluid, and transgender. From 1996 to 2004, Latinx student enrollment in STEM increased by 33\%, yet such students are less likely than their white counterparts to earn a degree or certificate in STEM; data from the Higher Education Research Institute (Hurtado et al., 2010) indicates that only $16 \%$ of Latinx students who were enrolled in college in 2004 as STEM majors completed a STEM degree, which means that $84 \%$ did not. This underrepresentation can be observed throughout the educational pipeline, leading to dismal numbers of Latinxs with doctorate degrees eligible to enter academia. The same is true for other people of color. As of 2013, only 6400 women of color with STEM doctorates held assistant, associate, or full professorships in universities, compared to 19,400 white women, 20,500 men of color, and 65,100 white men nationwide (Hess et al., 2013).

To increase the STEM workforce, Congress passed the America Competes Act in 2007 to authorize the development of more STEM programs at various educational levels. This same act was revisited in 2010 and established the President's Council of Advisors on Science and Technology; it incorporated additional requirements to strengthen the STEM educational pipeline for underrepresented minorities, primarily by funding programs aimed at attracting, keeping, and graduating underrepresented minorities in STEM fields. Later, the National Science Foundation was authorized to provide more funding to minority-serving institutions, such as Historically Black Colleges and Universities (HBCUs) and Hispanic Serving Institutions (HSIs).

Although the data show more Latinxs enrolling and graduating in STEM fields over time, the numbers of Latinas in academia remain low (Garcia, 2017). Research on Latinas in STEM is on the rise, but it rarely focuses on the low number of Latina academics specifically. In order to gain comprehensive knowledge about the many obstacles Latinas face in their pursuit of STEM-related academic careers, we need additional research to examine the factors both inside and outside the academy that facilitate (or hinder) their entrance into faculty positions. Likewise, we need more programs early in the pipeline that prepare undergraduates for doctoral studies; students, especially low-income and first-generation students, often lack the knowledge and resources to navigate the graduate school application process. Thus, faculty guidance and mentorship at this stage are essential for a smooth transition from undergraduate to graduate school.

\section{Identity Terminology}

To begin understanding the experiences of underrepresented students with Latin American heritage, we must acknowledge the diversity of identities within the Latinx community. Hispanic is defined by the U.S. Census as referring to "a person of Cuban, Mexican, Puerto Rican, South or Central American, or other Spanish culture or origin regardless of race." The Census further states that "Hispanics can be of any race, 
any ancestry, any ethnicity." This includes individuals from Europe and Spain. By contrast, Latina/o/ $x$ refers to a native, inhabitant, or descendant of a Latin American country (Salinas \& Lozano, 2017). The collective term Latinx is an identifier for a person of Latin American origin or descent and is used as a gender-neutral or nonbinary alternative to Latino or Latina. For example, people from Brazil would identify themselves as Latina/o/x, but would not necessarily consider themselves Hispanic.

Chicana/o/x is a chosen, political identity typically embraced by MexicanAmericans in the United States. Although Mexican-American and Chicano/a are sometimes used interchangeably, the latter term holds different meanings in various parts of the Southwest. Chicano/a became widely used during the Chicano Movement by Mexican-Americans to express pride in a shared cultural/ethnic and political identity. Chicanx is used as a gender-neutral or nonbinary alternative to Chicano and Chicana. Raza (meaning "race") is a term to unify the experiences of underrepresented and underserved Latinx communities in the United States, as well as those at the intersection of two or more racial or ethnic groups-Afro-Latino, for example. For many Latinx people, culture and language are at the foundation of their identity and affect the ways in which they interact with and navigate institutions.

Hispanic is the term typically employed in U.S. demographic data; therefore, researchers seeking to analyze Latinx must use data gathered under the Hispanic umbrella, which includes foreign- and national-born people of Latin American countries as well as those born in Spain or of Spanish ancestry. The qualitative social science research on Latinas in the U.S. academy that we have undertaken as part of the ADVANCE program at UC Davis (described in the Chapter, 'Making Visible the Invisible: Studying Latina STEM Scholars,') focuses on individuals who, for the most part, identify as Latina. As indicated in Fig. 1, we feel this distinction is

\section{Key Finding \#1:}

To begin understanding the experiences of underrepresented students with heritage from Latin American countries, we must acknowledge the diversity of identities within the Latinx community.

Fig. 1 The Latinx community is diverse 
important, because the experiences of Latina scholars, both positive and negative, differ from those of European descendants.

\section{Latinx Educational Pipeline}

The notion of an educational pipeline or pathway provides a useful analytical tool for viewing student progress as a continuum leading from elementary school into higher education. Rather than treating K-12 schooling and postsecondary education as separate entities, the pipeline (or pathway) enables us to see the patterns of student progress in terms of key transition points. The work of Pérez-Huber et al. (2015) as well as Yosso and Solórzano (2006) shows that the Latinx educational pipeline or pathway does not produce a student body representative of Latinx in the country.

Statistics gathered in 2006 by Yosso and Solórzano show that of 100 Latinx starting elementary school, only 46 would graduate from high school; of those high school graduates, only 26 would enroll in college. Of those 26 , only 17 would go to a community college and nine would start at a four-year institution. Of the 17 who started at community college, only one would transfer to a four-year institution. Of those at a four-year institution, eight would graduate with a degree, two would attend graduate or professional school, and a scant 0.2 of the original 100 will earn a doctoral degree (Yosso \& Solórzano, 2006). The researchers published a revised analysis of this pipeline in 2015 . Of the 100 Latinas and Latinos starting elementary school, 63 women and 60 men obtained a high school diploma. Thirteen women and 10 men obtained a bachelor's degree. Only four women and three men then obtained a graduate degree. Lastly, 0.3 women and 0.3 men obtained a doctorate degree (Yosso \& Solórzano, 2006). In a model of the pipeline in which students are disaggregated by country of origin, across the different nationalities, Chicanos or Chicanas and Salvadorans fare worse than Cubans and Puerto Ricans, who have higher educational attainments, as summarized in Fig. 2.

Note that these data reference the total numbers of Latinx students and not those who are specifically in STEM fields. We know little about the experiences of Latinxs either already working in STEM or interested in STEM fields. A study by Patricia Gándara found that Latinas are less likely to get a degree in a STEM area than are other women: only $3.5 \%$ of B.A.'s awarded in STEM fields in the United States in 2010 went to Latinas; only $17 \%$ of all bachelor's degrees awarded to Latinas in 2010 were in STEM, compared to $20 \%$ for black women, $23 \%$ for white women, and $33 \%$ for Asian women (Gándara, 2006).

A number of factors contribute to girls' and women's apparent lack of interest in science, including gender and race stereotypes. The literature finds that gender stereotypes start young, and that negative stereotypes lower girls' aspirations for science over time (Ambady et al., 2001). According to a study by Joan Williams and her colleagues, only $14 \%$ of teenage girls say they want to become a scientist. As the authors point out, gender and race stereotypes permeate both work and academic environments. They found that $65 \%$ of Latinas in STEM reported having to provide 


\section{Key Finding \#2: \\ Latinas are less likely to get a degree in a STEM area than other women; Cubans and Puerto Ricans have higher educational attainments than Chicanos/Chicanas and Salvadorans.}

Fig. 2 Latinas are less likely than are other women to get a STEM degree

more evidence of competence than others so as to prove themselves, which is a rate fairly consistent with their female colleagues from other ethnicities, and that both black and Latina women reported having been mistaken for either administrative or custodial staff. These findings reflect the apparent belief on the part of colleagues and coworkers that being a woman and being a scientist are incompatible (Williams et al., 2016). Such beliefs constitute a form of microaggression endured by womenparticularly women of color-in STEM environments.

\section{Challenges Facing STEM Latinx in U.S. Educational Institutions}

\section{Recruitment}

From elementary to high school, American students do not perform as well as their global counterparts in science and mathematics. On international science and mathematics comparison tests, Americans in $\mathrm{K}-12$ scored consistently at or below average; the national average test scores in 2015 were consistently lower than those of a number of developing countries (Kena et al., 2015; Russell et al., 2007; Swenson, 2015). Thus, part of the challenge facing U.S. institutions in encouraging students to pursue careers in STEM is to tackle a lack of education, training, and retention in STEM fields (Allen-Ramdial \& Campbell, 2014; Kuenzi, 2008).

Current efforts in education may be insufficient to generate lasting interest in STEM. Approximately $37.6 \%$ of non-underrepresented minorities and $34.8 \%$ of underrepresented minorities declare STEM majors as freshmen in college, yet a majority - consisting of disproportionately underrepresented minorities — drop out of their STEM majors before finishing their undergraduate studies. Even fewer 
continue in STEM fields at the graduate school level (Allen-Ramdial \& Campbell, 2014).

Among the possible challenges for underrepresented minority students are lower personal expectations and feelings of marginalization in STEM fields, a sense of cultural disconnection and isolation, lack of academic and social support, low socioeconomic status, and sociocultural forms of class disadvantage (Allen-Ramdial \& Campbell, 2014; Kates, 2011). As a result, many U.S. institutions have sought to address the increasing demand for scientific development and innovation by recruiting international students and workers, mainly from China and India (Chellaraj et al., 2008). Although this approach may eventually satisfy the need for a trained STEM workforce, it does not encourage students in the U.S. to pursue STEM fields, nor does it provide needed support for those who do (see Fig. 3).

Various programs and educational movements have been developed to improve STEM education nationwide. An example is the McNair Program, which encourages underrepresented minority (URM) undergraduates to seek research opportunities with sponsoring faculty and provides mentorship regarding graduate programs. However, most participating programs are underfunded, limited to certain locations, and disproportionately unavailable to the most underprivileged students.

Given the power of stereotypes to lower aspirations, research has shown the importance of ingraining STEM into an inclusive curriculum during children's elementary school years. Foundations for a STEM career must be laid early in the educational path of students, making it even more critical for colleges and universities to engage in the targeted recruitment and retention of women in STEM through, for example, mentoring and development programs. For Latinas, barriers to STEM are exacerbated by the lack of Latina role models (particularly role models in STEM), lesser access to educational capital, and a limited network of STEM professionals to serve as mentors.

\section{Key Finding \#3:}

From elementary to high school, U.S.

students do not perform as well as their

global counterparts in science and

\section{mathematics.}

Fig. 3 U.S. students underperform in STEM 


\section{Retention}

Role models are instrumental to the development of STEM students; indeed, the need for faculty of color in higher education has been emphasized in the literature for decades. This is not just because they mentor students of color; they also give those students a voice in the university system (Antonio, 2002; Ceja Alcalá et al., 2017; Mickelson \& Oliver, 1991; Piercy et al., 2005; Washington \& Harvey, 1989). Latinx and Chicanx faculty are more likely to introduce and orient Latinx and Chicanx students to postgraduate information than are other faculty, although at the same time this creates a service burden for both faculty and students who may lack the breadth of resources that their white counterparts enjoy (Ceja \& Rivas, 2010; Zambrana et al., 2017).

Research has found that students of color feel more comfortable approaching faculty of color because they share similar backgrounds, regardless of their academic interests or fields of study (Ceja \& Rivas, 2010; Ceja Alcalá et al., 2017). Essentially, having fewer faculty of color on campus can be a deterrent for Latinx students, lessening their likelihood of attending graduate school, as emphasized in Fig. 4. Despite the grossly inadequate representation of faculty of color in higher education, however, Latinx students remain proactive in seeking guidance to pursue advanced degrees(Ceja \& Rivas, 2010; Ceja Alcalá et al., 2017). Access to faculty of color in higher education not only has positive outcomes for students of color, it also exposes all students to URM faculty as "experts" who belong at the institution.

Quantitative research has documented the extent to which women and Latinas are underrepresented in higher education and, in particular, in STEM fields. For instance, Latinas represent only one percent of all occupations in computer science and engineering (Tornatzky et al., 2006; Taningco et al. 2008). But this research is generally unable to unpack and analyze the nuanced, on-the-ground reasons as to how and why Latinas end up in the careers they do, or how their personal, familial,

\section{Key Finding \#4:}

Not only does having access to faculty of
color in higher education have positive
outcomes for students of color, it also
exposes all students to URM faculty as
"experts" who belong at the institution.

Fig. 4 All students benefit from the presence of URM faculty 
and educational experiences shape their opportunities and the educational and career choices they make. Qualitative research, rather than quantitative research, is much better suited to investigate these issues.

\section{The Importance of Qualitative Research}

Qualitative research prioritizes the underlying factors contributing to the existence of a particular phenomenon (Merriam \& Grenier, 2019). Using a range of techniques, qualitative researchers can explore why people think, feel, believe, and behave in the ways that they do, thus generating new forms of knowledge. In-depth, semistructured interviewing is one such technique. This type of interviewing is time-consuming because research participants are invited to talk at length about their lives. In the interview-based study we conducted of Latina STEM scholars under the auspices of the ADVANCE Social Science Research Initiative (outlined in more detail below), participants often stated that they had never before been asked to talk about their experiences in academia. Likewise, transcribing and analyzing interview data are time-consuming because the meaning of people's own accounts is not always immediately self-evident. However, it is through interviewing, transcribing, and analyzing that we can begin to discern patterns of similarity and difference across cases and to see emerging connections - between various events in a participant's life as well as among participants with similar backgrounds. The sheer volume of data generated is immense and extremely rich.

The content-rich data generated by in-depth interviews enable an intersectional analysis not possible using only quantitative measures - in our case, an analysis of the intersection of gender, ethnicity, class, and language in reproducing social disadvantage. Such data can also reveal the microaggressions frequently experienced by marginalized groups, which we know shape the experiences of Latinas in STEM (see Zambrana, 2018).

\section{Insights from the Literature}

The benefits of qualitative research are especially relevant for conducting research with Latinas, whose numbers among STEM academics, as we have seen, are very small. When it comes to interviewing, different approaches yield different advantages. In structured interview research, each participant is asked the same questions with the exact same wording(Corbetta, 2003); this limits the time spent and potential subjective biases of the researcher, while giving her control of the topics and questions. Of course, "bias" can be built into topics and questions from the start, as is the case with any survey-style research. Structured interviews are typically preferred in sociodemographic data collection in which questions and responses are relatively straightforward (Doody \& Noonan, 2013). In unstructured interviews, researchers 
start with open-ended questions that invite participants to respond in great detail and therefore to play a more collaborative role in shaping the information gathered. Although prompts are established beforehand to get the conversation going, there are no restrictions on how participants respond or what they can talk about. Semistructured interviews are the most common among qualitative social scientists, and what we have used in our own research. They rely on a set of predetermined questions that are asked of all participants, but the researcher is free to rephrase them, seek clarification, ask follow-up questions, or ask questions off-script to explore important topics that emerge in situ (Doody \& Noonan, 2013; Fontana \& Frey, 1994; Mason, 2011).

Depending on the type of research being conducted, it can be important to consider key demographic or cultural characteristics of both researchers and research participants - qualities such as age, race, gender, nationality, religion, language, and the like (see Twine [2000] for a good discussion of these issues). For example, studies have shown that Latinas have a more difficult time answering questions on the subject of sexuality when being interviewed by men compared to women. Additionally, interviewers should be able to speak the language of preference to accommodate participants. Although rigorous standards exist for data collection, analysis, interpretation, and reporting qualitative data generally (Creswell, 1998; Emden \& Sandelowski, 1998; Lopez et al., 2008), and although research exists on cross-language contexts involving language barriers (Squires, 2009), few guidelines are in place specifically for conducting translinguistic qualitative research or for research with bilingual participants who may code-switch, meaning they may switch from one language to another or one style of speech to another depending on the topic of discussion and/or depending on their relationship to the interviewer. What we do know is that rephrasing or paraphrasing questions to match participants' level of knowledge, while remaining true to the research goals, can make both researcher and participant more comfortable with the research protocol at hand.

In our project, given the gender and racial/ethnic backgrounds of the research team (consisting of two bilingual Latina scholars and one English-speaking white scholar), we paid special attention to researcher positionality, often discussing and reflecting on our similarities and differences as together we coded and analyzed the data. It became evident early on that we brought different perspectives to the material and that our emerging interpretations were richer as a result of working collaboratively. As we note in Fig. 5, feminist scholars have long urged researchers to reflect on their position in the research process and on the power relations inherent in the production of knowledge (Fonow \& Cook, 1991; Harding, 1987, 2004; Harding \& Norberg, 2005; Sultana, 2007). At a large research-intensive university such as UC Davis, hierarchies of power exist in relation not solely to race and gender, but also to academic rank, title, and discipline. All three of us researchers are qualitative scholars in social science fields on a science-dominant campus, and only two of us have tenure-stream jobs-aspects of marginalization that we felt quite keenly at times as members of the ADVANCE effort.

Another concern of qualitative researchers is the degree of trust between researcher and participants. Trust is essential when conducting interviews because participants' 


\title{
Key Finding \#5:
}

\author{
Feminist scholars have long urged \\ researchers to reflect on their location in \\ the research process and on the power \\ relations inherent in the production of \\ knowledge.
}

Fig. 5 Power relations inevitably shape knowledge production

willingness to talk about their life experiences may depend in part on the quality of the researcher-participant relationship being established. Issues of privacy, anonymity, and confidentiality may also requires attention, especially in projects where participants feel vulnerable to being identified. These issues may arise because either the target population is small or it feels at risk of exposure for some reason (for example, being a victim of abuse, a political activist, an undocumented worker, or a member of a stigmatized group). In such cases, researchers should be prepared to ensure anonymity by omitting or altering any possible identifying information, while maintaining the integrity of the data and the project's goals.

When the target population is relatively small but geographically dispersed, simply finding potential participants can pose a challenge. A logical strategy when studying professionals is to seek out relevant professional organizations and associations. For example, we contacted several professional Latina STEM organizations to help disseminate information about our research and to facilitate the recruitment of participants. Interviewees could then suggest additional contacts within their networks, allowing us to grow our pool of interviewees through "snowball" sampling. As for conducting the interviews, we spoke with people in-person whenever possible, but otherwise, and more often, over the phone. Although face-to-face interviews are more commonly discussed in the literature, phone interviews provide a virtual space for communication in which topics can be explored in-depth and may even foster a welcome sense of security or anonymity when discussing sensitive topics(Mealer \& Jones, 2014; Prasad, 2015).

A growing literature has recently been exploring the benefits of conducting "culturally competent" qualitative research with Latinx populations, much of it stemming from community-engaged research (Flores et al., 2011). In this tradition, scholars and members of a community strive to collaborate equitably in studying issues affecting that community, with community involvement encouraged at every 
stage of the process, ranging from formulating research questions to disseminating results. With regard to Latinx populations, we see increasing calls to integrate Latinx cultural values into the research process. This means constituting culturally competent research teams that can minimize culture- and language-based biases and misunderstandings and prioritize Latinx values in identifying topics of concern, developing research protocols, recruiting participants, incentivizing participation, informing consent, and gathering data (whether through interviews or some other method).

Many educational studies with Latinx use what are called testimonios as a methodological, pedagogical, and activist tool in studying inequality and challenging social injustice (Bernal et al., 2017). Testimonios ("testimonials," meaning bearing witness) are first-person narratives that center the experience of the narrator; in educational contexts, they unveil the many and varied educational inequities that Latinx and Chicanx students face, highlighting students' resiliency and resistance in response (Bernal et al., 2017; Pérez-Huber \& Cueva, 2012). The use of testimonios challenges conventional assumptions that "the researcher knows best" and that objectivity is enhanced by distance; instead, the participant is herself a researcher of sorts, and her "findings" stem from her position in the midst of, and in companion with, a collective experience that may encompass marginalization, resistance, or oppression (Bernal et al., 2017).

Another widely used approach in research with Latinas goes by the name of "transformative mixed methods" (Mertens, 2010). Mertens claims that mixing quantitative and qualitative approaches is necessary if research is to generate social change. In her view, whereas qualitative data provide relatable perspectives that humanize research, quantitative data root those perspectives in a broader framework and generate credibility through the use of statistics and other quantitative measures, which is important for community members and scholars alike (Mertens, 2010).

\section{Gaps in the Literature}

Most of our knowledge about Latinas (often collectively called "Hispanics") in STEM is based on demographic data indicating that, in both industry and academia, representation for this group is particularly low. Additionally, we know that there are low numbers of Latinx College students enrolled in STEM fields, indicating continuing underrepresentation both in the industry workforce and in the academic pipeline. According to the U.S. Department of Education, only two percent of the STEM workforce is Hispanic, whereas almost $20 \%$ of the country's youth population is of Hispanic descent. In 2010, Hispanics accounted for $16 \%$ of the U.S. population, yet they received only eight percent of all STEM certificates and degrees awarded nationwide. These demographic data are for Hispanics as a whole; they are not disaggregated by culture, nation, or immigration history, and they include people from Spain as well as national and foreign-born Latinx from Mexico and from both 
Central and South America. Thus, we do not have accurate data on URMs; we only know that the existing numbers are inflated by foreign-born international Latinx.

Qualitative research can enrich demographic data by highlighting the experiences that lead to demographic outcomes. For example, it has revealed the marginality experienced by scholars of color, including underrepresented minority faculty in the United States, as they navigate often-hostile environments. So far, however, little qualitative research has examined the experiences of Latinas in academia, with even less examining the experiences of Latinas in STEM.

This literature, then, still leaves us with much uncharted territory. Taking into consideration the changing demographics of the country and the need for a diverse STEM workforce, we are left with some questions:

- What catalyzes an interest in science, leading Latinas to pursue an academic career in STEM?

- What interpersonal, familial, and sociocultural conditions have helped (and, conversely, hindered) Latinas in their pursuit of STEM careers, including their aspirations for parenting?

- What role do mentors and institutional support systems play in expanding the opportunities for Latinas in STEM?

- What are the everyday work experiences of Latinas in STEM fields at various stages of their educations and careers?

- How do Latinas in STEM experience the challenge of work-life balance in academia?

To answer such questions, it is imperative that researchers employ an intersectional approach. Intersectionality is an analytical tool for understanding the ways in which different social locations - gender, race, age, ethnicity, socioeconomic status, sexual orientation, and so on-intersect to shape both individual experience and the broader systems of power that individuals must navigate. To gain a deeper understanding of Latinas in STEM, therefore, we must analyze their experiences through an intersectional lens that accounts, at a minimum, for gender, class, and ethnicity, as well as differences of national origin (domestic vs. international) and language.

\section{The Social Science Research Initiative}

The Social Science Research Initiative, SSRI, is one of five ADVANCE initiatives at UC Davis. It aims to understand the career-path experiences of Latinas in STEM fields through two research studies whose findings helped shape the UC Davis ADVANCE program activities and will guide future funding. A central goal of this initiative is to attain a nuanced understanding of how Latinas progress in STEM, from their childhood through their academic careers. We examine holistically the obstacles and barriers as well as sources of support that shape the trajectory of Latina scientists in order to inform the campus recruitment and advancement of Latina STEM 
ladder-rank faculty, promote innovation in STEM fields, and contribute to a STEM workforce that is more representative of the demographics of California.

The first project was a quantitative survey of a sample U.S. Latina doctoral students. This survey documented respondents' perspectives on the barriers to entering and succeeding in STEM careers in academia, on ways to remove such barriers and better facilitate entry and eventual career success, and on the overall experience of Latinas in STEM doctoral programs. The project focused on graduate students because they represent the future of the Latina professoriate; we were particularly interested in the perspectives of those who are first-generation college students or first-generation graduate students. Our findings reveal that a majority of Latina graduate students have faculty advisors who are untenured, leading to funding insecurity, minimal or inadequate mentoring, and a longer time to completion of qualifying exams and eventual dissertations.

The second research project, ongoing, studies the career trajectories of 20 Latina STEM faculty, three other faculty of color in STEM fields, and 13 Latina social science faculty through in-depth, semi-structured interviews. This study seeks to understand the personal, familial, cultural, and structural influences that shape the pathway into and through an academic career. The interview protocol covers the lifespan of participants, beginning in childhood and ending at the present moment, to document how each life-stage is critical in its own right in building the foundation needed to pursue a successful career in academia. A deeper discussion of this study is presented in the Chapter, 'Making Visible the Invisible: Studying Latina STEM Scholars'.

\section{Conclusion}

This chapter argues that understanding the ways in which Latinx communities are marginalized is critical to diversity and inclusion efforts in the U.S. academy, particularly in STEM. Demographic data underscore the need to attract and maintain Latinas in STEM before and during their undergraduate education, thereby increasing the number who can enter graduate programs and subsequently pursue academic careers. Laying a foundation for resilience and success includes nurturing a scientist identity, enabling access to URM role models and programmatic supports, and better preparing students, post-doctoral scholars, and junior faculty alike for the institutional climates and cultures they will encounter. Finally, we must understand, value, and account for the ways in which gender, race, class, and other dimensions of difference and inequality intersect to structure one's experiences and opportunities, within and beyond the university. Such an intersectional approach is at the core of the Social Science Research Initiative as it seeks to understand the career pathways of Latina scholars in STEM. 


\section{References}

Allen-Ramdial, S.-A.A., \& Campbell, A. G. (2014). Reimagining the pipeline: Advancing STEM Diversity, persistence, and success. BioScience, 64(7), 612-618.

Ambady, N., Shih, M., Kim, A., \& Pittinsky, T. L. (2001). Stereotype susceptibility in children: Effects of identity activation on quantitative performance. Psychological Science, 12(5), 385-390.

Antonio, A. L. (2002). Faculty of color reconsidered: Reassessing contributions to scholarship. Journal of Higher Education, 73(5), 582-602.

Bernal, D. D., Burciaga, R., \& Carmona, J. F. (Eds.). (2017). Chicana/Latina testimonios as pedagogical, methodological, and activist approaches to social justice. Routledge.

Ceja Alcalá, J., Colón-Aguirre, M., Cooke, N. A., \& Stewart, B. (2017). A critical dialogue: Faculty of color in library and information science. InterActions: UCLA Journal of Education and Information Studies, 13(2). https://escholarship.org/uc/item/1gq2s8q5

Ceja, M., \& Rivas, M. (2010). Faculty-student interactions and Chicana PhD aspirations. Journal of the Professoriate, 3(2), 75-100.

Chellaraj, G., Maskus, K. E., \& Mattoo, A. (2008). The contribution of international graduate students to US innovation. Review of International Economics, 16(3), 444-462.

Corbetta, P. (2003). Social research: Theory, methods and techniques. Sage Publications.

Creswell, J. W. (1998). Qualitative inquiry and research design: Choosing among five traditions. Sage Publications.

Doody, O., \& Noonan, M. (2013). Preparing and conducting Interviews to collect data. Nurse Research, 20(5), 28-32.

Emden, C., \& Sandelowski, M. (1998). The good, the bad and the relative, part one: Conceptions of goodness in qualitative research. International Journal of Nursing Practice, 4(4), 206-212.

Flores, A. (2017). How the Hispanic population is changing. Pew Research Center. https://www. pewresearch.org/fact-tank/2017/09/18/how-the-u-s-hispanic-population-is-changing/

Flores, L. Y., Mendoza, M. M., Ojeda, L., He, Y., Meza, R. R., Medina, V., Ladehoff, J. W., \& Jordan, S. (2011). A qualitative inquiry of Latino immigrants' work experiences in the Midwest. Journal of Counseling Psychology, 58(4), 522-536.

Fonow, M. M., \& Cook, J. A. (Eds.). (1991). Beyond methodology: Feminist scholarship as lived research. Indiana University Press.

Fontana, A., \& Frey, J. (1994). The art of science. In The handbook of qualitative research. Sage Publications.

Gándara, P. (2006). Strengthening the academic pipeline leading to careers in math, science, and technology for Latino students. Journal of Hispanic Higher Education, 5(3), 222-237.

Garcia, G. A. (2017). Defined by outcomes or culture? Constructing an organizational identity for Hispanic-serving institutions. American Educational Research Journal, 54(1, suppl.), 111S$134 \mathrm{~S}$.

Harding, S. G. (Ed.). (1987). Feminism and methodology: Social science issues. Indiana University Press.

Harding, S. G. (Ed.). (2004). The feminist standpoint theory reader: Intellectual and political controversies. Routledge.

Harding, S., \& Norberg, K. (2005). New feminist approaches to social science methodologies: An introduction. Signs: Journal of Women in Culture and Society, 30(4), 2009-2015.

Hess, C., Gault, B., \& Yi, Y. (2013). Accelerating change for women faculty of color in STEM: Policy, action, and collaboration. Institute for Women's Policy Research. Washington, DC: Institute for Women's Policy Research. http://www.iwpr.org/publications/pubs/accelerating-changefor-women-faculty-of-color-in-stem-policy-action-and-collaboration

Hurtado, S., Newman, C. B., Tran, M. C., \& Chang, M. J. (2010). Improving the rate of success for underrepresented racial minorities in STEM fields: Insights from a national project. New Directions for Institutional Research, 2010(148), 5-15.

Kates, R. W. (2011). What kind of a science is sustainability science? Proceedings of the National Academy of Sciences, USA, 108(49), 19449-19450. 
Kena, G., Musu-Gillette, L., Robinson, J., Wang, X., Rathbun, A., Zhang, J., Wilkinson-Flicker, S., Barmer, A., \& Vélez, E. D. V. (2015). The condition of education 2015. NCES 2015-144. National Center for Education Statistics. https://nces.ed.gov/pubsearch/pubsinfo.asp?pubid=201 5144

Krogstad, J. M. (2014). With fewer new arrivals, Census lowers Hispanic population projections. Pew Research Center. https://www.pewresearch.org/fact-tank/2014/12/16/with-fewer-newarrivals-census-lowers-hispanic-population-projections-2/

Kuenzi, J. J. (2008). Science, technology, engineering, and mathematics (STEM) education: Background, federal policy, and legislative action. https://digitalcommons.unl.edu/crsdocs/35/

Lopez, G. I., Figueroa, M., Connor, S. E., \& Maliski, S. L. (2008). Translation barriers in conducting qualitative research with Spanish speakers. Qualitative Health Research, 18(12), 1729-1737.

Mason, J. (2011). Semistructured interview. In M. Lewis-Beck, A. Bryman, \& T. F. Liao (Eds.), The sage encyclopedia of social science research methods. Sage Publications.

Mealer, M., \& Jones, J. (2014). Methodological and ethical issues related to qualitative telephone interviews on sensitive topics. Nurse REsearcher, 21(4), 32-37.

Merriam, S. B., \& Grenier, R. S. (Eds.). (2019). Qualitative research in practice: Examples for discussion and analysis. Jossey-Bass.

Mertens, D. M. (2010). Transformative mixed methods research. Qualitative Inquiry, 16(6), 469474.

Mickelson, R. A., \& Oliver, M. L. (1991). Making the shortlist: Black candidates and the faculty recruitment process. In The racial crisis in American higher education (pp. 149-166).

Pérez-Huber, L., \& Cueva, B. M. (2012). Chicana/Latina testimonios on effects and responses to microaggressions. Equity \& Excellence in Education, 45(3), 392-410.

Pérez-Huber, L., Malagón, M. C., Ramirez, B. R., Gonzalez, L. C., Jimenez, A., \& Vélez, V. N. (2015). Still falling through the cracks: Revisiting the Latina/o education pipeline. CSRC Research Report. Number 19. UCLA Chicano Studies Research Center.

Piercy, F., Giddings, V., Allen, K., Dixon, B., Meszaros, P., \& Joest, K. (2005). Improving campus climate to support faculty diversity and retention: A pilot program for new faculty. Innovative Higher Education, 30(1), 53-66.

Prasad, P. (2015). Crafting qualitative research. Working in the Postpositivist Traditions. Routledge.

Russell, S. H., Hancock, M. P., \& McCullough, J. (2007). Benefits of undergraduate research experiences. Science, 316, 548-549.

Salinas, C., Jr., \& Lozano, A. (2017). Mapping and recontextualizing the evolution of the term Latinx: An environmental scanning in higher education. Journal of Latinos and Education, 2017, $1-14$.

Sonnert, G., Fox, M. F., \& Adkins, K. (2007). Undergraduate women in science and engineering: Effects of faculty, fields, and institutions over time. Social Science Quarterly, 88(5), 1333-1356.

Squires, A. (2009). Methodological challenges in cross-language qualitative research: A research review. International Journal of Nursing Studies, 46(2), 277-287.

Sultana, F. (2007). Reflexivity, positionality and participatory ethics: Negotiating fieldwork dilemmas in international research. ACME: An international E-journal for Critical Geographies, 6(3), 374-385.

Swenson, G. (2015). President's council of advisors on science and technology. U.S. Department of Education. National assessment of educational progress. https://obamawhitehouse.archives.gov/ administration/eop/ostp/pcast

Taningco, M. T. V., Mathew, A. B., \& Pachon, H. P. (2008). STEM professions: Opportunities and challenges for Latinos in science, technology, engineering, and mathematics. A Review of Literature. Tomas Rivera Policy Institute. https://eric.ed.gov/?id=ED502063

Tornatzky, L. G., Macias, E. E., Jenkins, D., \& Solis, C. (2006). Access and achievement: Building educational and career pathways for Latinos in advanced technology. Report on a National Study of Latino Access to Postsecondary Education and Careers in Information Technology. Tomas Rivera Policy Institute. https://eric.ed.gov/?id=ED502061 
Twine, F. W. (2000). Racial ideologies and racial methodologies. In Racing research, researching race: Methodological dilemmas in critical race studies (pp. 1-34).

Washington, V., \& Harvey, W. (1989). Affirmative rhetoric, negative action: African-American and Hispanic faculty at predominantly white institutions. ASHE-ERIC Higher Education Reports. George Washington University.

Williams, J. C., Phillips, K. W., \& Hall, E. V. (2016). Tools for change: Boosting the retention of women in the stem pipeline. Journal of Research in Gender Studies, 6(11).

Yosso, T. J., \& Solórzano, D. G. (2006). Leaks in the Chicana and Chicano educational pipeline. Latino Policy \& Issues Brief, No. 13. UCLA Chicano Studies Research Center.

Zambrana, R. E. (2018). Toxic ivory towers: The consequences of work stress on underrepresented minority faculty. Rutgers University Press.

Zambrana, R. E., Dávila, B. A., Espino, M. M., Lapeyrouse, L. M., Valdez, R. B., \& Segura, D. A. (2017). Mexican American faculty in research universities: Can the next generation beat the odds? Sociology of Race and Ethnicity, 3(4), 458-473.

Open Access This chapter is licensed under the terms of the Creative Commons Attribution 4.0 International License (http://creativecommons.org/licenses/by/4.0/), which permits use, sharing, adaptation, distribution and reproduction in any medium or format, as long as you give appropriate credit to the original author(s) and the source, provide a link to the Creative Commons license and indicate if changes were made.

The images or other third party material in this chapter are included in the chapter's Creative Commons license, unless indicated otherwise in a credit line to the material. If material is not included in the chapter's Creative Commons license and your intended use is not permitted by statutory regulation or exceeds the permitted use, you will need to obtain permission directly from the copyright holder. 